\title{
Experimental, quantum chemical studies of oxazole derivatives as corrosion inhibitors on mild steel in molar hydrochloric acid medium
}

\section{H. Rahmani, ${ }^{1,2}$ F. El-Hajjaji, ${ }^{1} *$ A. El Hallaoui, ${ }^{2}$ M. Taleb, ${ }^{1}$ Z. Rais, ${ }^{1}$ M. El Azzouzi, ${ }^{3}$ B. Labriti, ${ }^{2}$ K. Ismaily Alaoui ${ }^{1}$ and B. Hammouti ${ }^{3}$ \\ ${ }^{1}$ Laboratory of Engineering, Electrochemistry, Modeling and Environment (LIEME),} Faculty of Sciences, University Sidi Mohamed Ben Abdellah, Fez, Morocco ${ }^{2}$ Laboratory of organical Chemistry (LOC), Faculty of sciences, University Sidi Mohamed Ben Abdellah, Fez, Morocco

${ }^{3}$ Laboratory of Applied Analytical Chemistry Materials and Environment (LC2AME), Faculty of sciences, University of Mohammed Premier, Oujda, Morocco

*E-mail: el.hajjajifadoua25@gmail.com

\begin{abstract}
The corrosion inhibition performances of (4-ethyl-2-phenyl-4,5-dihydro-1,3-oxazol-4-yl)methanol (C1); 4-\{[(4-ethyl-2-phenyl-4,5-dihydro-1,3-oxazol-4-yl)methoxy]methyl $\}$ benzene-1-sulfonate (C2) and 4-[(azidoxy)methyl]-4-ethyl-2-phenyl-4,5-dihydro-1,3oxazole (C3) mild steel in molar hydrochloric solution have been evaluated by using gravimetric, electrochemical impedance spectroscopy (EIS) and potentiodynamic polarization techniques as well as quantum chemical calculations. Results obtained reveal that these compounds reduce significantly the corrosion rate of mild steel, their inhibition efficiencies increased with inhibitor concentration. This behavior means that the inhibitive effect of the studied oxazole derivatives occur through the adsorption of inhibitor molecules on the metal surface. Polarization curves reveal that both compounds $\mathrm{C} 1$ and $\mathrm{C} 3$ act essentially as mixed type inhibitors with cathodic predominance effect, while the compound $\mathrm{C} 2$ can be classified as cathodic type inhibitor. EIS spectra obtained show a typical Nyquist plot with single semicircles shifted along the real impedance of $\mathrm{x}$-axis. Impedance data are analyzed in term of the simple modified Randles equivalent circuit with one relaxation time constant. Indeed, a Constant phase element, CPE, is introduced in the circuit instead of a pure double layer capacitor in order to take into account the electrode surface heterogeneity. Adsorption of these inhibitors on the mild steel surface was found to obey the Langmuir adsorption isotherm. Some thermodynamic parameters were calculated and discussed. The correlation between inhibition efficiency and molecular structure of oxazole derivatives was theoretically studied via quantum chemical calculations using density functional theory (DFT) at B3LYP/6-31G (d,p). Results showed a general correlation between the computed descriptors and the experimental data.
\end{abstract}

Keywords: oxazole, polarization curves, EIS measurement, mild steel, DFT study. 
Received: June 10, 2018. Published: October 29, 2018

doi: $\underline{10.17675 / 2305-6894-2018-7-4-3}$

\section{Introduction}

Protection of metals and alloys from corrosion represent an important challenge for industries. Several approaches have been designed to protect metallic installations against this phenomenon. However, the use of inhibitors is one of the best-known and the most cost-effective methods to avoid or prevent destruction or deterioration of the metal surface $[1,2]$. In general, the organic compounds containing heteroatom with a high electronic density such as oxygen, sulphur, and nitrogen atoms, or those containing $\pi$ electrons in triple or conjugated double bonds are usually effective inhibitors for steel corrosion $[3,4]$. Furthermore, the molecules that, simultaneously, include nitrogen and Sulfur in their structures are of particular importance. Numerous studies report [5-7] that the compounds containing both nitrogen and sulphur in their structure provide excellent inhibition properties compared with those containing only sulphur or nitrogen.

On the other hand, it is generally assumed that the organic compounds inhibit the steel dissolution by adsorption on the metal surface blocking the actives corrosion sites. Their efficiencies depend on the nature and charge of the metal surface, the type of corrosive medium and the chemical structure of inhibitor $[6,8]$.

Adsorption can be essentially described by two mean types of interactions which are : physical adsorption involving electrostatic forces between the ionic charges or dipoles of the adsorbed species and the electrical charge at the metal/solution interface. And chemical adsorption, which involves the sharing of charge or charge transfer of inhibitory molecules to the metal surface to form coordinate types of bond $[7,9]$.

Theoretical calculations have been widely used in order to establish any relationship between quantum chemical calculations and experimental inhibition efficiencies of the inhibitors [10].

Among abundant suggestions for acid corrosion inhibitors, azole compounds have gained a great attention. Indeed, several azoles derivatives have been reported to be effective as corrosion inhibitors for steel and copper in acidic media [11-13, 18]. In our laboratory, many azole derivatives such as pyrazole [14-16] and Benzimidazole [17] compounds have been recently studied as corrosion inhibitors for mild steel in hydrochloric acid, and have been shown a good inhibition properties,

This paper aimed to evaluate the corrosion inhibitive activity of three newly synthesized phenyl oxazol substituted compounds namely, (4-ethyl-2-phenyl-4,5-dihydro1,3-oxazol-4-yl)methanol (C1); 4-\{[(4-ethyl-2-phenyl-4,5-dihydro-1,3-oxazol-4-yl)methoxy]methyl $\}$ benzene-1-sulfonate (C2) and 4 -[(azidoxy)methyl]-4-ethyl-2-phenyl4,5-dihydro-1,3-oxazole (C3) (Figure 1) on mild steel in $1 \mathrm{M} \mathrm{HCl}$ solution, using gravimetric study, potentiodynamic polarization, and electrochemical impedance spectroscopy. Quantum chemical calculations were performed in order to ascertain any correlation between inhibition efficiencies and structure of oxazole derivatives. 
$\mathrm{C} 1$

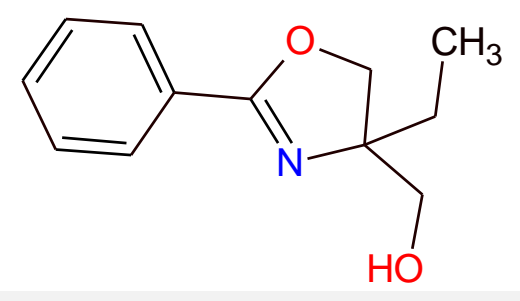

(4-Ethyl-2-phenyl-4,5-dihydro-1,3-oxazol-4-yl)methanol

$\mathrm{C} 2$

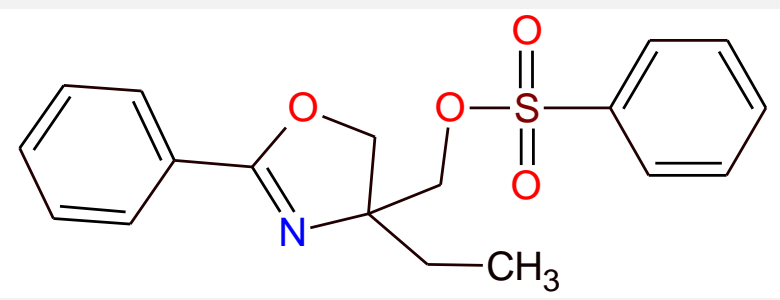

4-\{[(4-Ethyl-2-phenyl-4,5-dihydro-1,3-oxazol-4-yl)methoxy]methyl\}benzene-1-sulfonate

C3

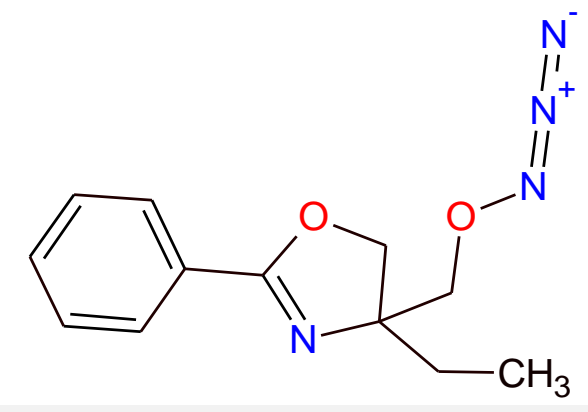

4[(Azidooxy)methyl]-4-ethyl-2-phenyl-4,5-dihydro-1,3-oxazole

Figure 1. Chemical molecular structures of oxazole derivatives.

\section{Experimental details}

\subsection{Synthesis of inhibitors}

C1: (4-Ethyl-2-phenyl-4,5-dihydro-1,3-oxazol-4-yl)methanol is prepared by condensation of 2-amino-2-ethylpropane-1,3-diol with benzoic acid at reflux in xylene.

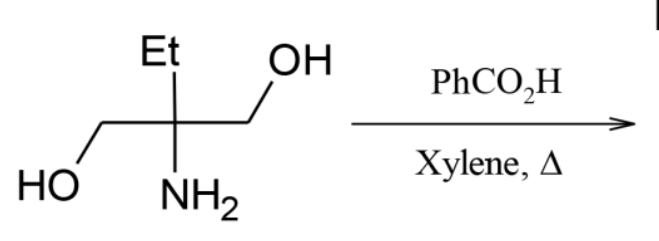<smiles>CCC1(CO[18OH])COC(c2ccccc2)=N1</smiles> 
C2: The action of tosyl chloride in pyridine at $0^{\circ} \mathrm{C}$ on (4-ethyl-2-phenyl-4,5-dihydro1,3-oxazol-4-yl)methanol gives 4-\{[(4-ethyl-2-phenyl-4,5-dihydro-1,3-oxazol-4-yl)methoxy]methyl \}benzene-1-sulfonate.
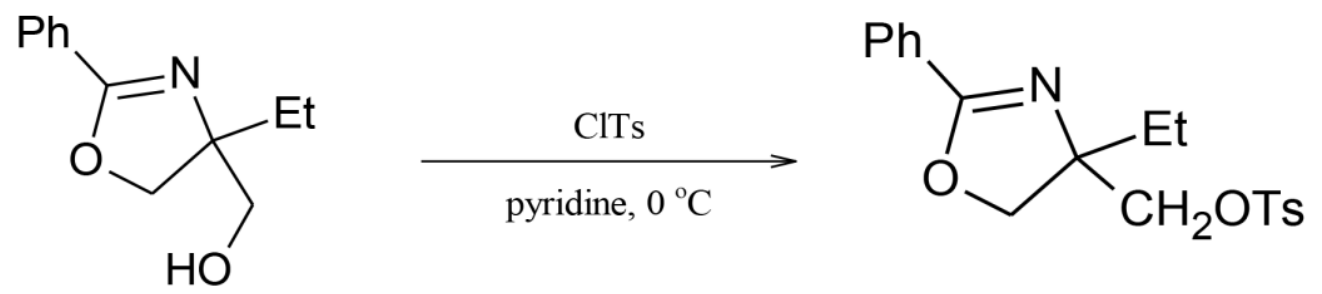

C3: The reaction of sodium azide with 4-\{[(4-ethyl-2-phenyl-4,5-dihydro-1,3-oxazol4-yl)methoxy]methyl \}benzene-1-sulfonate in dimethyl formamide (DMF) gives, after 48 hours of heating to $120^{\circ} \mathrm{C} 4$-[(azidooxy)methyl]-4-ethyl-2-phenyl-4,5-dihydro-1,3-oxazole.
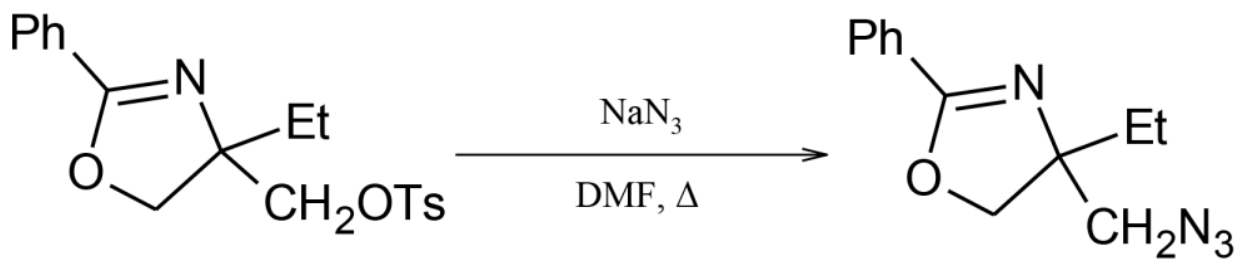

\subsection{Materials and solutions}

Mild steel strips with the composition of (wt. \%): $0.21 \% \mathrm{C}, 0.38 \% \mathrm{Si}, 0.05 \% \mathrm{Mn}, 0.05 \%$ $\mathrm{S}, 0.09 \% \mathrm{P}, 0.01 \% \mathrm{Al}$ and balance $\mathrm{Fe}$ were used for electrochemical and weight loss measurements. For all experiments, the mild steel specimens were polished using a sequence of emery papers of different grades (from 180 to 1200), degreased with acetone and rinsed with distilled water.

\subsection{Methods}

\subsubsection{Gravimetric study}

Gravimetric experiments were executed according to standard methods using the thermostatic cooling condenser at rang of temperature from $308 \mathrm{~K}$ to $338 \mathrm{~K}$.After weighing accurately, the soft steel samples with dimension of $(2 \mathrm{~cm} \times 1 \mathrm{~cm} \times 0.2 \mathrm{~cm})$ are immersed vertically in the corrosive solution in the absence and the presence of investigated inhibitors. After the corrosion test, the specimens were carefully washed in double distilled water, dried and then weighted. The values of inhibition efficiency $\eta_{\mathrm{WL}}(\%)$ are calculated as follow:

$$
\eta_{\mathrm{WL}}(\%)=\frac{W_{\mathrm{corr}}-W^{\prime}{ }_{\text {inh }}}{\mathrm{w}_{\mathrm{corr}}} \times 100
$$

where $W_{\text {corr }}$ and $W_{\text {inh }}^{\prime}$ are the values of the corrosion rate in the absence and presence of inhibitor respectively. 


\subsubsection{Electrochemical study}

Potentiodynamic polarization and electrochemical impedance spectroscopy (EIS) were performed in a three-electrode glass cell: a platinum electrode (CE) as the auxiliary electrode, a saturated calomel electrode (SCE) as the reference electrode (all potentials given in this study were referred to this reference electrode) and a mild steel with a surface of $1 \mathrm{~cm}^{2}$ as the working electrode (WE). The electrochemical study was carried out using a potentiostat Radiometer-analytical PGZ100 piloted by Voltamaster 4 software at room temperature. Electrochemical impedance spectroscopy plots were recorded after the open circuit potential reached a steady state for $30 \mathrm{~min}$. All the experiments were conducted over a frequency domain between $100 \mathrm{kHz}$ to $100 \mathrm{mHz}$. A small signal $(10 \mathrm{mV}$ ac peak-topeak voltage) was applied. Potentiodynamic polarization curves were obtained in the presence and the absence of the inhibitors in the solution. Both cathodic and anodic directions were recorded between $-800 \mathrm{mV}$ to $-200 \mathrm{mV}$ under a scan rate of $1 \mathrm{mV} \mathrm{s}^{-1}$. In order to determine the corrosion current values, the linear Tafel segments, in a large domain of potential, of the cathodic curves were extrapolated to the corresponding corrosion potentials.

\subsubsection{Calculation method}

The quantum theoretical calculations were performed by means of Gaussian-09 software package [19]. Calculations were carried out at the DFT level employing the B3LYP/ 6-31G $(\mathrm{d}, \mathrm{p})$ basis set taking into account exchange and correlation. Indeed, the B3LYP method uses Becke's three-parameter functional including a mixture of HF with DFT exchange terms associated with the gradient-corrected correlation functional of Lee, Yang and Parr (LYP) [20]. However, because of the good balance between computational cost and achievable accuracy, DFT has become the most popular method for electronic structure calculations.

Geometry optimizations for all studied molecules were undertaken without any symmetry constraints. The quantum chemical parameters were calculated for all studied molecules in gas as well as in aqueous phase. Polarized Continuum Model (PCM) developed by Tomasi et al. [21] was used in order to get a better approach of the experimental results acquired in aqueous solution, such model based on the representation of the liquid by polarizable dielectric continuum having the static dielectric constant of water $(\varepsilon=78.39)$. Indeed, water was used to include the solvent effect because we cannot represent the implicit effect of hydrogen chloride [22].

As a result, some main global reactivity descriptors such as: energy of HOMO ( $\left.E_{\mathrm{HOMO}}\right)$, energy of the LUMO $\left(E_{\mathrm{LUMO}}\right)$, the energy gap $\Delta E_{\text {gap }}$ between $E_{\mathrm{HOMO}}$ and $E_{\mathrm{LUMO}}$, dipole moment $(\mu)$, electronegativity $(\chi)$, electron affinity $(A)$, global hardness $(\eta)$, ionization potential $(I)$ and the fraction of electrons transferred $(\Delta N)$ were determined and discussed. In addition, some local reactivity parameters such as atomic populations and Fukui indices were also calculated in order to provide information on the nucleophilic and electrophilic behavior of the oxazole derivatives. 


\section{Results and discussion}

\subsection{Tafel polarization measurements}

Polarization measurements were carried out to determine the effect of oxazole derivatives studied on the electrochemical behavior of mild steel in $1 \mathrm{M}$ hydrochloric acid. Tafel polarization curves for mild steel in $1 \mathrm{M} \mathrm{HCl}$ media in the absence and presence of various concentrations of the oxazole compounds under study are shown in Figure 2.
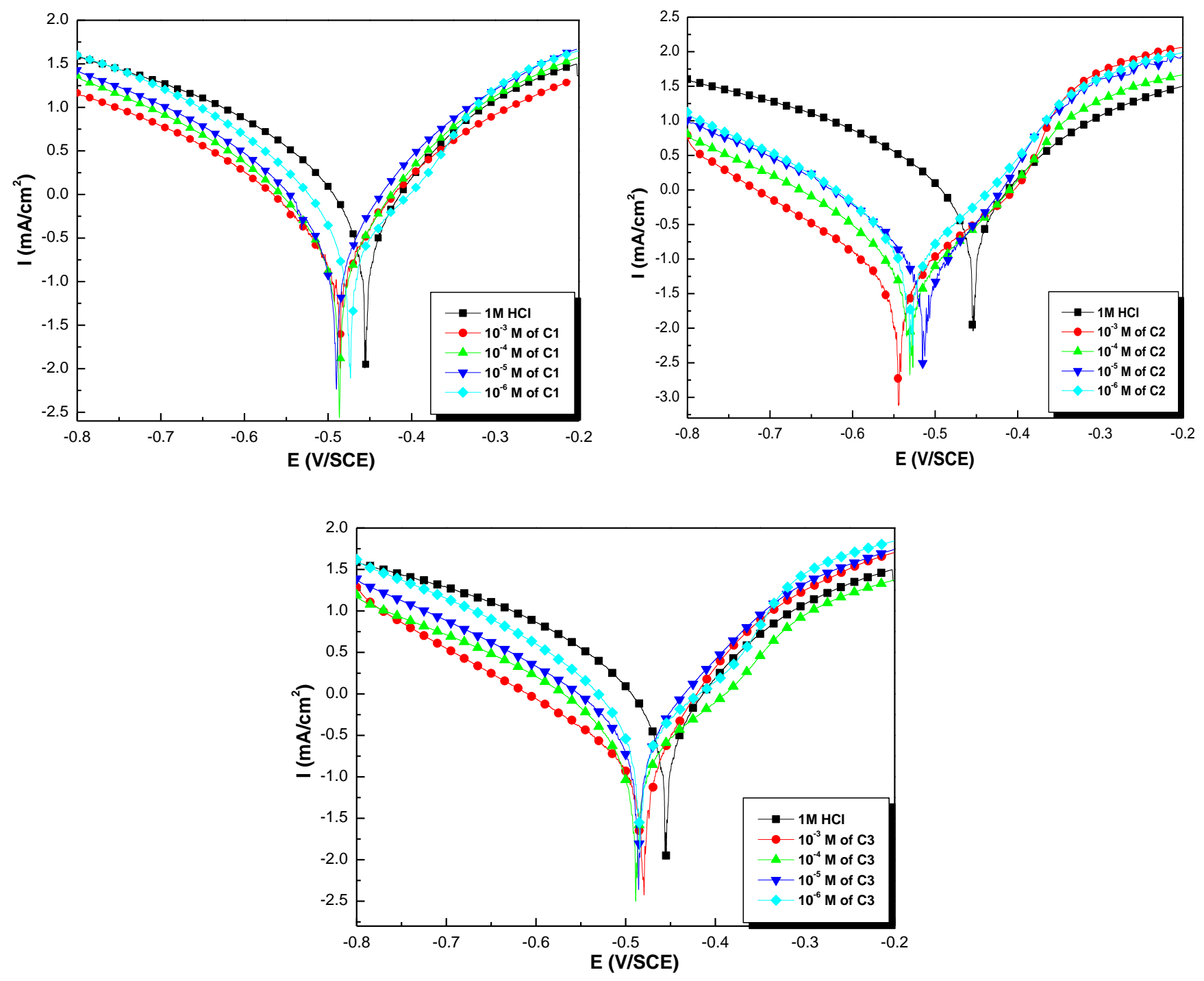

Figure 2. Tafel polarization curves for mild steel in $1 \mathrm{M} \mathrm{HCl}$ without and with different concentration of $\mathrm{C} 1, \mathrm{C} 2$ and $\mathrm{C} 3$ compounds.

The cathodic potential diagrams give rise to parallel lines indicating that the addition of inhibitor molecules does not change the hydrogen evolution mechanism. Thus, the hydrogen reduction on the mild steel surface occurs mainly through a charge transfer mechanism [23]. Moreover, the small variation of the cathodic Tafel slopes $\left(\beta_{c}\right)$ suggest 
that the hydrogen evolution reaction, is activation controlled and the addition of oxazole derivatives does not modify the mechanism of this process.

As it is reported in the literature [24], use of both anodic and cathodic slopes for determination of currents density is certainly preferred. However, the use of only one of either the cathodic or the anodic regions is recognized [25]. In the present investigation, the corrosion current densities were obtained by only extrapolating the cathodic Tafel plots to the corresponding corrosion potential. Indeed, the anodic region of polarization curves does not display Tafel behavior which is very apparent in the presence of compound C2. Accordingly, there is an ambiguity and source of error in the numerical values of the anodic Tafel slopes calculated by the Ec-Lab software. This is the reason why values of the anodic Tafel slopes are not included here.

The inhibition efficiency was calculated by using the following equation [26]:

$$
\eta_{\text {Tafel }} \%=\frac{I_{\text {corr }}-I_{\text {corr }}^{\prime}}{I_{\text {corr }}} \times 100
$$

Where $I_{\text {corr }}$ and $I_{\text {corr }}^{\prime}$ represent the corrosion current densities of mild steel in the absence and the presence of inhibitor respectively.

The obtained data such as the corrosion potentials $\left(E_{\text {corr }}\right)$, corrosion current densities $\left(I_{\text {corr }}\right)$, cathodic Tafel slopes $\left(\beta_{c}\right)$ and the corresponding corrosion inhibition efficiencies are given in Table 1.

Table 1. Electrochemical polarization parameters for mild steel in $1 \mathrm{M} \mathrm{HCl}$ without and with different concentration of $\mathrm{C} 1, \mathrm{C} 2$ and $\mathrm{C} 3$.

\begin{tabular}{|c|c|c|c|c|c|}
\hline Medium & $\begin{array}{c}\text { Concentration } \\
\text { (M) }\end{array}$ & $\begin{array}{c}E_{\text {corr }} v s \text { SCE } \\
(\mathrm{mV})\end{array}$ & $\begin{array}{c}i_{\text {corr }} \\
\left(\mu \mathrm{A} / \mathbf{C m}^{2}\right)\end{array}$ & $\left|\beta_{\mathrm{c}}\right|\left(\mathrm{mV} \operatorname{dec}^{-1}\right)$ & $\underset{\%}{\eta_{\text {Tafel }}}$ \\
\hline $1 \mathrm{M} \mathrm{HCl}$ & 00 & -456 & 1072 & 176 & \\
\hline \multirow{4}{*}{$\mathrm{C} 1$} & $10^{-3}$ & -485 & 228.5 & 165 & 78.6 \\
\hline & $10^{-4}$ & -486 & 426 & 162 & 60.2 \\
\hline & $10^{-5}$ & -490 & 613 & 162 & 42.8 \\
\hline & $10^{-6}$ & -473 & 678 & 153 & 36.7 \\
\hline \multirow{4}{*}{$\mathrm{C} 2$} & $10^{-3}$ & -543 & 56 & 138 & 94.7 \\
\hline & $10^{-4}$ & -528 & 124 & 152 & 88.4 \\
\hline & $10^{-5}$ & -515 & 179 & 148 & 83.3 \\
\hline & $10^{-6}$ & -528 & 259 & 152 & 75.8 \\
\hline \multirow{4}{*}{$\mathrm{C} 3$} & $10^{-3}$ & -479 & 151 & 160 & 85.9 \\
\hline & $10^{-4}$ & -489 & 390 & 182 & 63.6 \\
\hline & $10^{-5}$ & -485 & 453 & 171 & 57.7 \\
\hline & $10^{-6}$ & -484 & 647 & 163 & 39.6 \\
\hline
\end{tabular}


Inspection of Figure 2 and Table 1 reveals that the current density decreases clearly with the increase of the inhibitor concentrations for all inhibitor. This behavior could be attributed to the increase in adsorption of inhibitor at the metal/solution interface.

Generally, an inhibitor act as a cathodic or anodic type if the corrosion potential value was shifted more than $85 \mathrm{mV}$ compared with that of the blank solution [27, 28]. It is clear from Figure 2 and Table 1 that the addition of the three studied inhibitors decreases markedly the current density on the cathodic branch, while a small decrease is registered in the anodic branch.

Furthermore, the corrosion potential is slightly moved into the cathodic direction in the presence of various concentrations of $\mathrm{C} 1$ and $\mathrm{C} 3$. The maximum displacement in $E_{\text {corr }}$ value was $34 \mathrm{mV}$ these results suggest that both compounds mainly act as mixed-type inhibitors with a predominant cathodic effect. Whereas a marked displacement of potential toward more negative potentials can be clearly observed for $\mathrm{C} 2$, the largest displacement obtained in the values of $E_{\text {corr }}$ was about $87.6 \mathrm{mV}(>85 \mathrm{mV})$. Thus $\mathrm{C} 2$ can be classified as cathodic type inhibitor.

The compound $\mathrm{C} 2$ prove the best inhibition effect, this performance could be due to the availability of $\pi$ electrons and more surface what leads to a bigger adsorption on the metallic surface $[29,30]$.

\subsection{Electrochemical impedance spectroscopy (EIS)}

Electrochemical impedance spectroscopy is a convenient technique in investigating corrosion mechanisms [31]. The corrosion behaviour of mild steel in $1 \mathrm{M} \mathrm{HCl}$ without and with various inhibitors concentration was investigated by EIS at $298 \mathrm{~K}$ after $30 \mathrm{~min}$ of immersion. Figure 3 illustrates the Nyquist plots obtained without and with studied inhibitors. All the impedance spectra were measured at the corresponding open-circuit potentials and are analyzed in term of equivalent circuit shown in Figure 3.

EIS spectra obtained exhibit a typical Nyquist plot with single semicircles shifted along the real impedance of x-axis, Electrochemical impedance spectroscopy (EIS) measurements showed that the dissolution process of steel occurred under activation control. Impedance experimental data revealed a frequency distribution of the capacitance, simulated as constant phase element.

As it can be observed from Figure 3, the impedance plots acquired with $1 \mathrm{M} \mathrm{HCl}$ in the absence and the presence of the three inhibitors at different attentions, they didn't show a perfects semicircles, this behavior is usually referred to the frequency dispersion which has been attributed to the inhomogeneities of the metal surface or its roughness during the corrosion process, generally the frequency dispersion is frequently modeled by use of constant phase element (CPE) [32, 33].

The Nyquist plots for mild steel in corrosive medium with and without the studied inhibitors were modeled by a simple Randles circuit (Figure 4), which is a solution resistance $\left(R_{\mathrm{s}}\right)$ in series with a parallel combination of the charge-transfer resistance $\left(R_{\mathrm{ct}}\right)$ and the constant phase element (CPE) [34]. 

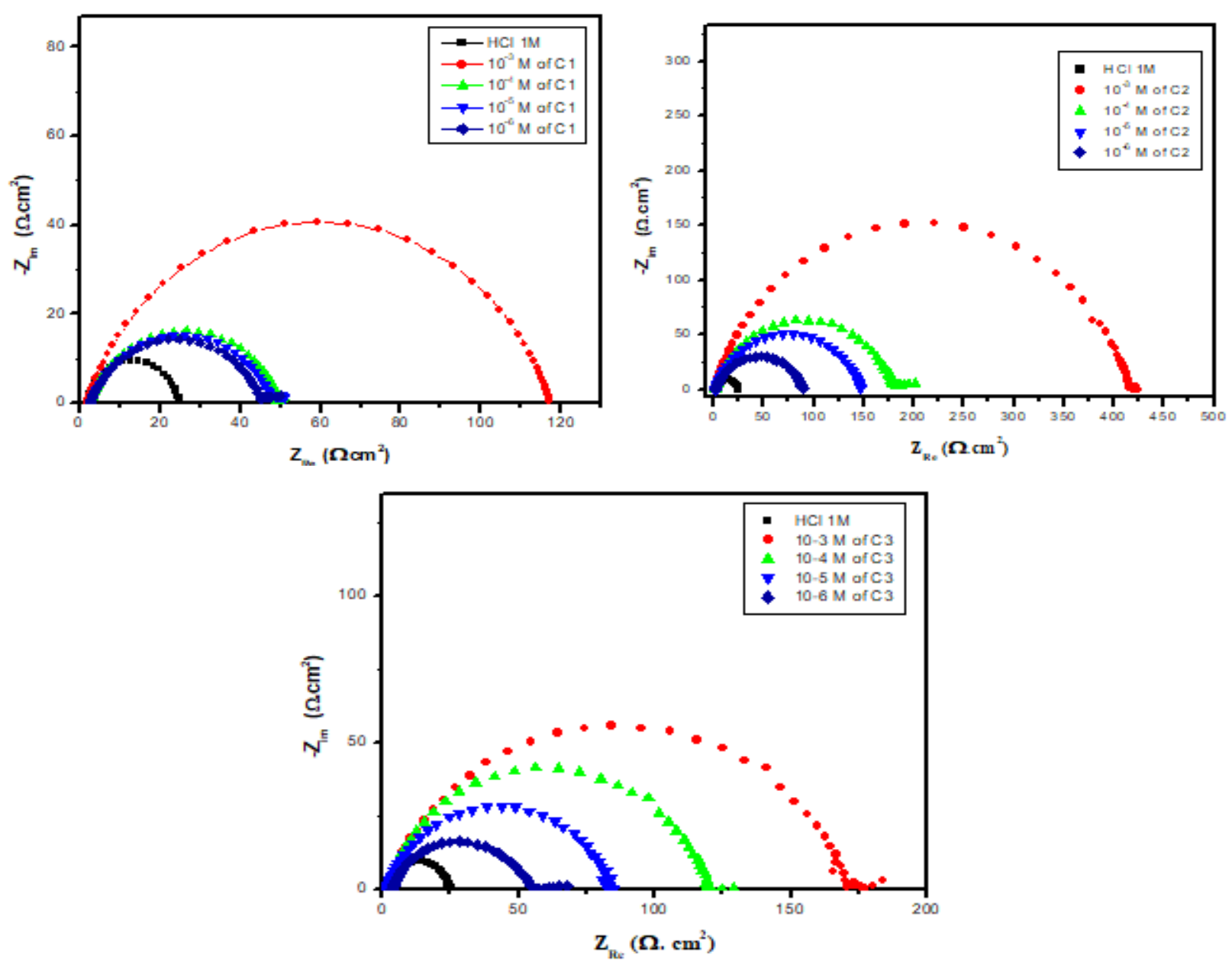

Figure 3. Nyquist plots of EIS measurements for mild steel in $1 \mathrm{M} \mathrm{HCl}$ without and with different concentrations of $\mathrm{C} 1, \mathrm{C} 2$ and $\mathrm{C} 3$.

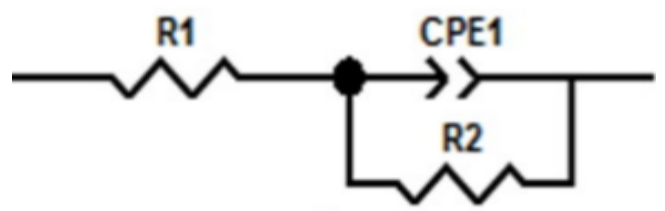

Figure 4. Electrical equivalent circuit used to fit the EIS data of the interface mild steel / $1 \mathrm{M}$ $\mathrm{HCl}$ solution without and with investigated inhibitors.

The experimental plots were very well fitted according to the proposed equivalent circuit and electrochemical impedance parameters obtained from the recorded EIS spectrum in the Table 2 the inhibition efficiency IE\% was calculated by the charge transfer resistance values for different concentrations of compounds using the following equation $[35,36]$.

$$
E_{R \mathrm{ct}} \%=\frac{R_{\mathrm{ct} / \mathrm{inh}}-R_{\mathrm{ct}}}{R_{\mathrm{ct} / \mathrm{inh}}} \times 100
$$

Where $R_{\mathrm{ct}}$ and $R_{\mathrm{ct} / \mathrm{inh}}$ are the charge-transfer resistance values without and with inhibitor, respectively. 
Table 2. Electrochemical impedance parameters of different concentration of tested compounds $\mathrm{C} 1, \mathrm{C} 2$ and $\mathrm{C} 3$ for the corrosion of mild steel in $1 \mathrm{M} \mathrm{HCl}$.

\begin{tabular}{|c|c|c|c|c|c|c|}
\hline Medium & $\begin{array}{l}\text { Concentration } \\
\left(\mathrm{mol} \mathrm{l}^{-1}\right)\end{array}$ & $\begin{array}{c}R \mathrm{~s} \\
\left(\boldsymbol{\Omega} \cdot \mathbf{c m}^{2}\right)\end{array}$ & $n$ & $\begin{array}{c}R_{\mathrm{ct}} \\
\left(\boldsymbol{\Omega} \cdot \mathrm{cm}^{2}\right)\end{array}$ & $\begin{array}{c}C_{\mathrm{dl}} \\
\left(\mu \mathrm{F} \cdot \mathrm{cm}^{-2}\right)\end{array}$ & $E_{R \mathrm{Rt}}(\%)$ \\
\hline $1 \mathrm{M} \mathrm{HCl}$ & 00 & 2.07 & 0.831 & 22.8 & 151.6 & - \\
\hline \multirow{4}{*}{$\begin{array}{c}1 \mathrm{M} \mathrm{HCl} / \\
\mathrm{Cl}\end{array}$} & $10^{-3}$ & 1.89 & 0.784 & 105.5 & 123.5 & 78.4 \\
\hline & $10^{-4}$ & 2.5 & 0.762 & 47.7 & 146.1 & 52.2 \\
\hline & $10^{-5}$ & 2.7 & 0.752 & 45.7 & 147.7 & 50 \\
\hline & $10^{-6}$ & 2.4 & 0.750 & 43.2 & 155.7 & 47 \\
\hline \multirow{4}{*}{$\begin{array}{c}1 \mathrm{M} \mathrm{HCl} / \\
\mathrm{C} 2\end{array}$} & $10^{-3}$ & 1.08 & 0.803 & 415.3 & 39.7 & 94.5 \\
\hline & $10^{-4}$ & 1.65 & 0.781 & 179.9 & 68.8 & 87.3 \\
\hline & $10^{-5}$ & 1.74 & 0.776 & 145.7 & 88.7 & 84.3 \\
\hline & $10^{-6}$ & 1.82 & 0.766 & 87.4 & 96.6 & 74 \\
\hline \multirow{4}{*}{$\begin{array}{c}1 \mathrm{M} \mathrm{HCl} / \\
\mathrm{C} 3\end{array}$} & $10^{-3}$ & 2.2 & 0.772 & 166.1 & 56.2 & 86 \\
\hline & $10^{-4}$ & 2.0 & 0.805 & 116.9 & 94.9 & 80 \\
\hline & $10^{-5}$ & 1.7 & 0.782 & 81.9 & 95.5 & 72 \\
\hline & $10^{-6}$ & 2.8 & 0.758 & 41.7 & 129.1 & 45 \\
\hline
\end{tabular}

Examination of the table above reveals that the addition of the inhibitors decreases the values of the double layer capacity $C_{\mathrm{dl}}$ and increases that of the charge transfer resistance $R_{\mathrm{ct}}$. The decrease in the $C_{\mathrm{dl}}$ value can be attributed the adsorption of the molecules of the inhibitor to the surface of the steel forming a protective layer [37]. Furthermore, the decrease of the $n$ value after addition of studied compounds when compared to that obtained in blank can be explained by some increase in the initial surface inhomogeneity [38]. The values of efficiencies obtained from the impedance measurements are comparable and run parallel with those obtained from the weight loss measurements and the potentiodynamic polarization method.

\subsection{Effect of temperature}

The temperature is important factors that can influence the corrosion process by modify electrode/solution in the uninhibited or the inhibited medium [39]. The study of the temperature effect was performed in the range of temperature $308-338 \mathrm{~K}$. All the results obtained were represented in Table 3.

Table 3 reveals that the rate of corrosion increases as the temperature increases in the absence and presence of these inhibitors. Moreover, this increase is more pronounced without investigated inhibitors. These results show that, at high temperatures, these 
inhibitors do not exhibit a well-marked inhibitory character; hence a high-temperature application of these compounds is not conceivable [40,41].

Table 3. Inhibition efficiency values for mild steel in $1 \mathrm{M} \mathrm{HCl}$ without and with different compounds at $10^{-3} \mathrm{M}$ after $2 \mathrm{~h}$ immersion period.

\begin{tabular}{|c|c|c|c|c|c|c|c|c|}
\hline \multirow[b]{2}{*}{$\begin{array}{c}\text { Temperature } \\
\text { (K) }\end{array}$} & \multicolumn{2}{|c|}{$1 \mathrm{M} \mathrm{HCl}$} & \multicolumn{2}{|l|}{ C1 } & \multicolumn{2}{|l|}{ C2 } & \multicolumn{2}{|l|}{$\mathrm{C3}$} \\
\hline & $\begin{array}{c}W_{\text {corr }} \\
\left(\mathbf{m g} / \mathbf{c m}^{2} \cdot \mathbf{h}\right)\end{array}$ & IE\% & $\begin{array}{c}W_{\text {corr }} \\
\left(\mathbf{m g} / \mathbf{c m}^{2} \cdot \mathbf{h}\right)\end{array}$ & IE\% & $\begin{array}{c}W_{\text {corr }} \\
\left(\mathbf{m g} / \mathbf{c m}^{2} \cdot \mathbf{h}\right)\end{array}$ & IE\% & $\begin{array}{c}W_{\text {corr }} \\
\left(\mathbf{m g} / \mathbf{c m}^{2} \cdot \mathbf{h}\right)\end{array}$ & IE\% \\
\hline 308 & 0.8517 & - & 0.2003 & 76 & 0.0591 & 93 & 0.1351 & 84 \\
\hline 318 & 1.6898 & - & 0.4168 & 75 & 0.122 & 92 & 0.3705 & 78 \\
\hline 328 & 3.8596 & - & 0.96 & 75 & 0.424 & 89 & 1.1047 & 71 \\
\hline 338 & 6.1541 & - & 1.947 & 68 & 1.0167 & 83 & 1.842 & 70 \\
\hline
\end{tabular}

3.3.1 Thermodynamic parameters of the activation corrosion

The thermodynamic activation parameters such as the activation apparent energy $E_{\mathrm{a}}$, the activation enthalpy $\Delta H^{*}$ and the activation entropy $\Delta S^{*}$ were calculated from the Arrhenius equation (4) and the transition state equation (5) [42, 43].

$$
\begin{gathered}
W_{\text {corr }}=A \exp \left(-\frac{E_{\mathrm{a}}}{R T}\right) \\
I_{\text {corr }}=\frac{R T}{N h} \exp \left(\frac{\Delta S_{\mathrm{a}}}{R}\right) \exp \left(\frac{\Delta H_{\mathrm{a}}}{R T}\right)
\end{gathered}
$$

Where $W_{\text {corr }}$ is the corrosion rate, $\left(R=8.314 \mathrm{~J} \cdot \mathrm{mol}^{-1} \cdot \mathrm{K}^{-1}\right), T$ is the absolute temperature [44], $A$ is the Arrhenius pre-exponential constant, $\left(K_{\mathrm{B}}=1.38066 \cdot 10^{-23} \mathrm{~J} \cdot \mathrm{K}^{-1}\right), h$ is the Plank's constant, $\Delta H^{*}$ is the activation enthalpy and $\Delta S^{*}$ is the activation entropy [45].

All the activation parameters values for mild steel in the corrosive medium at different concentrations of compounds $\mathrm{C} 1, \mathrm{C} 2$ and $\mathrm{C} 3$ are listed in the Table 4.

Table 4. Activation parameters of the dissolution reaction of mild steel in $1 \mathrm{M} \mathrm{HCl}$ in the absence and

\begin{tabular}{|c|c|c|c|}
\hline Inhibitor & $\mathrm{Ea}\left(\mathrm{kJ} \cdot \mathrm{mol}^{-1}\right)$ & $\Delta H^{*}\left(\mathbf{k J} \cdot \mathbf{m o l}^{-1}\right)$ & $\Delta S^{*}\left(\mathrm{~kJ} \cdot \mathrm{mol}^{-1} \cdot \mathbf{K}^{-1}\right)$ \\
\hline none & 58.5 & 55.8 & -64.9 \\
\hline $\mathrm{C} 1$ & 66.2 & 63.5 & -52.3 \\
\hline $\mathrm{C} 2$ & 84.5 & 81.84 & -3.8 \\
\hline $\mathrm{C} 3$ & 77.5 & 74.8 & -18.3 \\
\hline
\end{tabular}
presence of three compounds at $10^{-3} \mathrm{M}$. 
The energies of the activations of the three compounds are superior to those of the acid medium. This result confirms that our molecules are adsorbed into the surface of the metal by forming physical bonds (physisorption) [46]. Furthermore, positive signs of activation enthalpies revels the endothermic nature of the process of dissolving steel.

\subsubsection{Adsorption isotherm}

The inhibition of corrosion of metals by organic compounds is explained by their adsorption. The latter described by two to main types: physical and chemical adsorption.

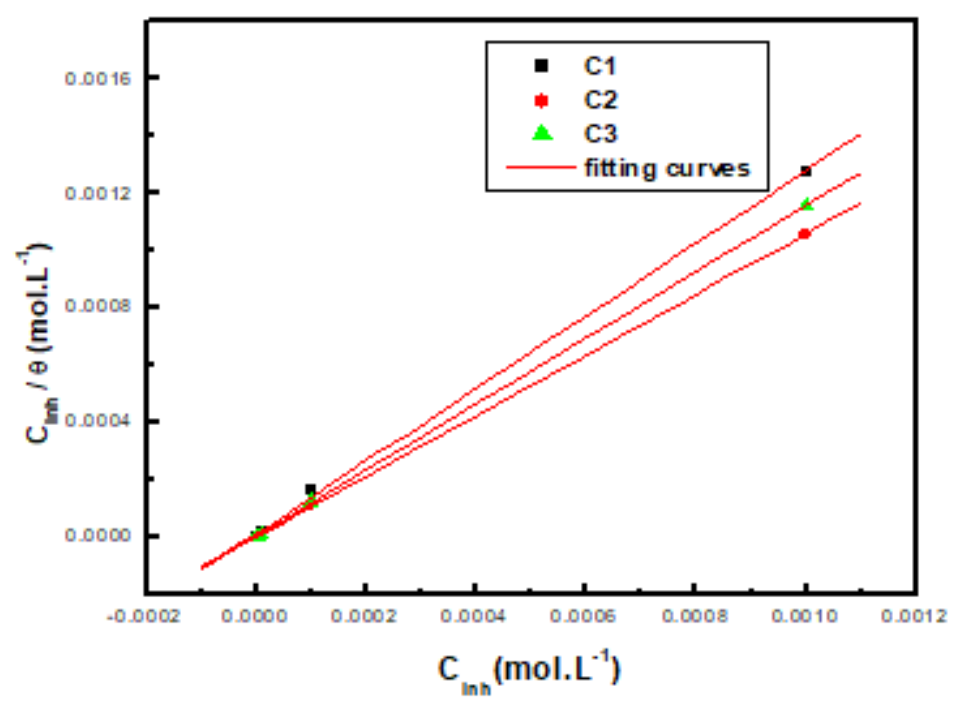

Figure 5. Langmuir adsorption plots for mild steel in $1 \mathrm{M} \mathrm{HCl}$ containing different concentrations of oxazole derivatives at $T=298 \mathrm{~K}$.

The adsorption isotherm was plotted by the variation of the $C / \theta$ ratio as a function of the concentration represents some straight line in the presence of the three inhibitors in the aggressive medium, the slopes and correlation factors values $\left(R^{2}\right)$ are close to suggest that the inhibitors studied were adsorbed into the surface of the steel obeying to the Langmuir adsorption isotherm.

The surface coverage $\theta$ is related to the equilibrium adsorption constant $K_{\text {ads }}$ as follow [47]:

$$
\frac{C_{\mathrm{inh}}}{\theta}=\frac{1}{K_{\mathrm{ads}}}+C_{\mathrm{inh}}
$$

Where $C_{\text {inh }}$ is the inhibitor concentration

$$
\Delta G_{\mathrm{ads}}=-R T \ln \left(55.55 K_{\mathrm{ads}}\right)
$$

Where $\Delta G_{\text {ads }}$ is the free energy adsorption.

The values of $\Delta G_{\text {ads }}$ are all very close to $-40 \mathrm{~kJ} / \mathrm{mol}$, which implies electron charging or transfer between the molecules of the studied inhibitors and the surface of the metal to form bond, is chemisorptions [48]. 
Table 5. Thermodynamic parameters for the adsorption of studied compounds at $298 \mathrm{~K}$ on mild steel in $1 \mathrm{M} \mathrm{HCl}$ at different concentrations $\left(10^{-3}, 10^{-4}, 10^{-5}\right.$ and $\left.10^{-6} \mathrm{M}\right)$.

\begin{tabular}{|c|c|c|}
\hline Inhibitors & $\boldsymbol{K}_{\text {ads }}(\mathbf{L} / \mathbf{m o l})$ & $\Delta \boldsymbol{G}_{\text {ads }}\left(\mathbf{k J} \cdot \mathbf{m o l}^{\mathbf{1}}\right)$ \\
\hline $\mathrm{C} 1$ & $6.05 \cdot 10^{4}$ & -37.2 \\
\hline $\mathrm{C} 2$ & $2.90 \cdot 10^{5}$ & -41.1 \\
\hline $\mathrm{C} 3$ & $2.45 \cdot 10^{5}$ & -40.7 \\
\hline
\end{tabular}

As result, from all thermodynamic parameters for activation and adsorption process, it is suggested that the three compounds were adsorbed onto the mild steel surface by involve both physisorption and chemisorptions interaction.

\section{Quantum chemical study}

The geometry of the inhibitors molecules were determined by optimizing the structural parameters at B3LYP/6-31G (d. p) using the Gaussian 09 program package [49].

\subsection{Global molecular reactivity}

Frontier molecular orbital ( $E_{\mathrm{HOMO}}$ is the highest occupied molecular orbital energy, and $E_{\mathrm{LUMO}}$ is the lowest unoccupied molecular orbital energy) allows understanding the adsorption process of the molecules onto the metal surface [50,51]. The electron affinity $(A)$ and the ionization potential $(I)$ are related respectively to the $\left(E_{\mathrm{LOMO}}\right)$ and the energy $\left(E_{\mathrm{HUMO}}\right)$.

$$
A=-E_{\mathrm{LOMO}} ; I=-E_{\mathrm{HUMO}}
$$

The parameters such as the global hardness $(\eta)$, and the electro-negativity $(\chi)$ were calculated by the next equations [52].

$$
\chi=\frac{I+A}{2} \quad \eta=\frac{I-A}{2}
$$

Table 6. The calculated quantum chemical parameters for structures of tested compounds at B3LYP/6$31 \mathrm{G}(\mathrm{d} . \mathrm{p})$ level of theory in gas $(\mathrm{G})$ and in aqueous phases (A).

\begin{tabular}{ccccccccc}
\hline Inhibitor & phase & $\begin{array}{c}\boldsymbol{E}_{\text {HOMO }} \\
(\mathbf{e v})\end{array}$ & $\begin{array}{c}\boldsymbol{E}_{\text {LUMO }} \\
(\mathbf{e v})\end{array}$ & $\begin{array}{c}\Delta \boldsymbol{E} \\
(\mathbf{e v})\end{array}$ & $\begin{array}{c}\boldsymbol{\mu} \\
(\mathbf{D})\end{array}$ & $\begin{array}{c}\eta \\
(\mathbf{e v})\end{array}$ & $\begin{array}{c}\boldsymbol{\chi} \\
(\mathbf{e v})\end{array}$ & $\Delta \boldsymbol{N}$ \\
\hline \multirow{2}{*}{$\mathrm{C} 1$} & $\mathrm{G}$ & -6.280 & -0.943 & 5.337 & 1.245 & 2.669 & 3.612 & 0.635 \\
& $\mathrm{~A}$ & -6485 & -1.146 & 5.339 & 1.466 & 2.669 & 3.815 & 0.596 \\
\hline \multirow{2}{*}{$\mathrm{C} 2$} & $\mathrm{G}$ & -6.439 & -1.197 & 5.242 & 4.937 & 2.621 & 3.819 & 0.607 \\
& $\mathrm{~A}$ & -6.604 & -1.263 & 5.341 & 6.647 & 2.671 & 3.933 & 0.574 \\
\hline \multirow{2}{*}{$\mathrm{C} 3$} & $\mathrm{G}$ & -6.505 & -1.161 & 5.344 & 2.001 & 2.672 & 3.833 & 0.592 \\
& $\mathrm{~A}$ & -6.574 & -1.230 & 5.344 & 2.468 & 2.672 & 3.902 & 0.579 \\
\hline
\end{tabular}


The low values of energy gap can indicate the ease of removing an electron from the HOMO orbital to LUMO $[33,34]$, this increase the chance of getting better inhibition efficiency. The energy gap, $\Delta E=\left(E_{\mathrm{LUMO}}-E_{\mathrm{HOMO}}\right)$, is important parameter and it is a function of the reactivity of the inhibitor. As $\Delta E$ decreases, the reactivity of the molecule increases to increase the inhibition efficiency of the molecule [53]. It can be concluded from Table 6 that $\mathrm{C} 2$ is more efficient in gas than the other cases respecting the order of the inhibition efficiency obtained experimentally.

\subsection{Local molecular reactivity}

The Fukui indices are used to obtain the detail information of local reactivity [54]. The condensed Fukui functions are calculated using the following equations [55]:

$$
\begin{gathered}
f_{k}^{+}=P_{k}(N+1)-P_{k}(N) \\
f_{k}^{-}=P_{k}(N)-P_{k}(N-1) \\
f_{k}^{0}=\frac{1}{2}\left[P_{k}(N+1)-P_{k}(N-1)\right]
\end{gathered}
$$

Where $P_{k}$ is the gross charge of $k$ atom, the $P_{k}(N+1), P_{k}(N)$ and $P_{k}(N-1)$ are defined as the charge of the anionic, neutral and cationic species respectively. The calculated Fukui indices for nucleophilic and electrophilic attack for the three studied inhibitors are presented in Table 7.

\begin{tabular}{|c|c|c|c|c|c|c|c|c|}
\hline Inhibitor & Atom & Phase & $\boldsymbol{P}_{N}$ & $\boldsymbol{P}_{N+1}$ & $\boldsymbol{P}_{N-1}$ & $f_{k}^{+}$ & $f_{k}^{-}$ & $f_{k}^{0}$ \\
\hline \multirow{14}{*}{$\mathrm{C} 1$} & \multirow{2}{*}{$\mathrm{C} 3$} & G & 5.427 & 5.510 & 5.411 & 0.083 & 0.015 & 0.049 \\
\hline & & $\mathrm{A}$ & 5.427 & 5.509 & 5.411 & 0.082 & 0.016 & 0.049 \\
\hline & \multirow{2}{*}{ N6 } & $G$ & 7.525 & 7.658 & 7.290 & 0.133 & 0.235 & 0.184 \\
\hline & & A & 7.525 & 7.657 & 7.289 & 0.132 & 0.235 & 0.184 \\
\hline & \multirow{2}{*}{$\mathrm{O} 7$} & G & 8.544 & 8.570 & 8.455 & 0.026 & 0.088 & 0.057 \\
\hline & & A & 8.544 & 8.570 & 8.455 & 0.0258 & 0.088 & 0.0571 \\
\hline & \multirow{2}{*}{$\mathrm{C} 8$} & $\mathrm{G}$ & 6.120 & 6.199 & 6.064 & 0.079 & 0.056 & 0.067 \\
\hline & & $\mathrm{A}$ & 6.119 & 6.200 & 6.064 & 0.080 & 0.055 & 0.067 \\
\hline & \multirow{2}{*}{$\mathrm{C} 9$} & $\mathrm{G}$ & 6.191 & 6.261 & 6.133 & 0.070 & 0.057 & 0.064 \\
\hline & & A & 6.1911 & 6.2617 & 6.13387 & 0.070 & 0.057 & 0.063 \\
\hline & \multirow{2}{*}{$\mathrm{C} 10$} & $\mathrm{G}$ & 6.203 & 6.266 & 6.180 & 0.062 & 0.022 & 0.042 \\
\hline & & A & 6.203 & 6.26613 & 6.18019 & 0.063 & 0.02291 & 0.042 \\
\hline & \multirow{2}{*}{$\mathrm{C} 15$} & $\mathrm{G}$ & 6.224 & 6.367 & 6.107 & 0.142 & 0.116 & 0.129 \\
\hline & & $\mathrm{A}$ & 6.224 & 6.36722 & 6.107 & 0.143 & 0.116 & 0.129 \\
\hline
\end{tabular}

Table 7. Pertinent natural population and Fukui functions of the studied inhibitors calculated at B3LYP/6$31 \mathrm{G}(\mathrm{d}, \mathrm{p})$ in gas $(\mathrm{G})$ and aqueous $(\mathrm{A})$ phases. 


\begin{tabular}{|c|c|c|c|c|c|c|c|c|}
\hline Inhibitor & Atom & Phase & $\boldsymbol{P}_{N}$ & $P_{N+1}$ & $P_{N-1}$ & $f_{k}^{+}$ & $f_{k}^{-}$ & $f_{k}^{0}$ \\
\hline \multirow{20}{*}{$\mathrm{C} 2$} & \multirow{2}{*}{$\mathrm{C} 3$} & $\mathrm{G}$ & 5.420 & 5.46595 & 5.41205 & 0.04534 & 0.00856 & 0.02695 \\
\hline & & A & 5.42018 & 5.46442 & 5.41351 & 0.04424 & 0.00667 & 0.025455 \\
\hline & \multirow{2}{*}{ N6 } & $\mathrm{G}$ & 7.52995 & 7.58352 & 7.35137 & 0.05357 & 0.17858 & 0.116075 \\
\hline & & A & 7.53082 & 7.58333 & 7.36267 & 0.05251 & 0.16815 & 0.11033 \\
\hline & \multirow{2}{*}{$\mathrm{O} 7$} & $\mathrm{G}$ & 8.53943 & 8.55811 & 8.47619 & 0.01868 & 0.06324 & 0.04096 \\
\hline & & A & 8.53894 & 8.55715 & 8.47835 & 0.01821 & 0.06059 & 0.0394 \\
\hline & \multirow{2}{*}{$\mathrm{C} 8$} & $\mathrm{G}$ & 6.12241 & 6.15494 & 6.07179 & 0.03253 & 0.05062 & 0.041575 \\
\hline & & A & 6.12244 & 6.15451 & 6.07887 & 0.03207 & 0.04357 & 0.03782 \\
\hline & \multirow{2}{*}{ C9 } & $\mathrm{G}$ & 6.18998 & 6.2244 & 6.14567 & 0.03442 & 0.04431 & 0.039365 \\
\hline & & A & 6.18997 & 6.22366 & 6.14913 & 0.03369 & 0.04084 & 0.037265 \\
\hline & \multirow{2}{*}{$\mathrm{C} 10$} & $G$ & 6.20079 & 6.23388 & 6.18213 & 0.03309 & 0.01866 & 0.025875 \\
\hline & & A & 6.20059 & 6.23292 & 6.18239 & $\mathbf{0 . 0 3 2 3 3}$ & 0.0182 & 0.025265 \\
\hline & \multirow{2}{*}{$\mathrm{C} 15$} & $\mathrm{G}$ & 6.22198 & 6.29889 & 6.12396 & 0.07691 & 0.09802 & 0.087465 \\
\hline & & A & 6.22166 & 6.29811 & 6.13029 & 0.07645 & 0.09137 & 0.08391 \\
\hline & \multirow{2}{*}{ C33 } & G & 6.35385 & 6.41976 & 6.32009 & 0.06591 & 0.03376 & 0.049835 \\
\hline & & A & 6.35871 & 6.42532 & 6.31606 & 0.06661 & 0.04265 & 0.05463 \\
\hline & \multirow{2}{*}{$\mathrm{C} 35$} & $G$ & 6.21283 & 6.25337 & 6.2187 & 0.04054 & -0.00587 & 0.017335 \\
\hline & & A & 6.21004 & 6.25212 & 6.21893 & 0.04208 & -0.00889 & 0.016595 \\
\hline & \multirow{2}{*}{$\mathrm{C} 40$} & $G$ & 6.00436 & 6.09578 & 5.95236 & 0.09142 & 0.052 & 0.07171 \\
\hline & & A & 6.0026 & 6.09496 & 5.94076 & 0.09236 & 0.06184 & 0.0771 \\
\hline \multirow{12}{*}{$\mathrm{C} 3$} & \multirow{2}{*}{$\mathrm{C} 3$} & $G$ & 5.42293 & 5.49131 & 5.4138 & 0.06838 & 0.00913 & 0.038755 \\
\hline & & A & 5.42282 & 5.49077 & 5.41332 & 0.06795 & 0.0095 & 0.038725 \\
\hline & \multirow{2}{*}{ N6 } & $\mathrm{G}$ & 7.52759 & 7.61573 & 7.32885 & 0.08814 & 0.19874 & 0.14344 \\
\hline & & A & 7.52797 & 7.61619 & 7.32796 & 0.08822 & 0.20001 & 0.144115 \\
\hline & \multirow{2}{*}{$\mathrm{O} 7$} & $\mathrm{G}$ & 8.54096 & 8.56625 & 8.47341 & 0.02529 & 0.06755 & 0.04642 \\
\hline & & A & 8.5407 & 8.56596 & 8.47276 & 0.02526 & 0.06794 & 0.0466 \\
\hline & \multirow{2}{*}{$\mathrm{C} 8$} & $\mathrm{G}$ & 6.12305 & 6.17299 & 6.06095 & 0.04994 & 0.0621 & 0.05602 \\
\hline & & A & 6.12273 & 6.17358 & 6.0611 & 0.05085 & 0.06163 & 0.05624 \\
\hline & \multirow{2}{*}{ C9 } & $\mathrm{G}$ & 6.19001 & 6.2417 & 6.13926 & 0.05169 & 0.05075 & 0.05122 \\
\hline & & A & 6.19009 & 6.24184 & 6.13963 & 0.05175 & 0.05046 & 0.051105 \\
\hline & \multirow{2}{*}{$\mathrm{C} 10$} & $\mathrm{G}$ & 6.20166 & 6.25048 & 6.18032 & 0.04882 & 0.02134 & 0.03508 \\
\hline & & A & 6.20168 & 6.25062 & 6.18023 & 0.04894 & 0.02145 & 0.035195 \\
\hline
\end{tabular}




\begin{tabular}{ccccccccc}
\hline Inhibitor & Atom & Phase & $\boldsymbol{P}_{\boldsymbol{N}}$ & $\boldsymbol{P}_{N+\mathbf{1}}$ & $\boldsymbol{P}_{N-\mathbf{1}}$ & $\boldsymbol{f}_{\boldsymbol{k}}^{+}$ & $\boldsymbol{f}_{\boldsymbol{k}}^{-}$ & $\boldsymbol{f}_{\boldsymbol{k}}^{\mathbf{0}}$ \\
\hline \multirow{2}{*}{$\mathrm{C} 15$} & $\mathrm{G}$ & 6.22186 & 6.33174 & 6.10836 & $\mathbf{0 . 1 0 9 8 8}$ & $\mathbf{0 . 1 1 3 5}$ & 0.11169 \\
& $\mathrm{~A}$ & 6.22173 & 6.33218 & 6.10823 & $\mathbf{0 . 1 1 0 4 5}$ & $\mathbf{0 . 1 1 3 5}$ & $\mathbf{0 . 1 1 1 9 7 5}$ \\
\cline { 2 - 8 } $\mathrm{N} 29$ & $\mathrm{G}$ & 7.35675 & 7.40543 & 7.30622 & $\mathbf{0 . 0 4 8 6 8}$ & $\mathbf{0 . 0 5 0 5 3}$ & 0.049605 \\
& $\mathrm{~A}$ & 7.35495 & 7.40273 & 7.30523 & $\mathbf{0 . 0 4 7 7 8}$ & $\mathbf{0 . 0 4 9 7 2}$ & 0.04875 \\
\hline \multirow{2}{*}{$\mathrm{N} 30$} & $\mathrm{G}$ & 6.78344 & 6.83124 & 6.79201 & 0.0478 & -0.00857 & 0.019615 \\
& $\mathrm{~A}$ & 6.7836 & 6.83074 & 6.79219 & 0.04714 & -0.00859 & 0.019275 \\
\hline \multirow{2}{*}{$\mathrm{N} 31$} & $\mathrm{G}$ & 7.06738 & 7.2177 & 6.95195 & $\mathbf{0 . 1 5 0 3 2}$ & $\mathbf{0 . 1 1 5 4 3}$ & 0.132875 \\
& $\mathrm{~A}$ & 7.07063 & 7.21997 & 6.95527 & $\mathbf{0 . 1 4 9 3 4}$ & $\mathbf{0 . 1 1 5 3 6}$ & 0.13235 \\
\hline
\end{tabular}

The Fukui indices make it possible to compare the reactivity of different sites within the same molecular system. Atoms C1, C2 and C3 have the highest $f_{k}^{+}$values, indicating that these are probably the preferred sites in the case of a nucleophilic attack. Whereas the $\mathrm{O} 7$ and $\mathrm{O} 29$ atoms for $\mathrm{C} 1 \mathrm{O} 7, \mathrm{O} 29, \mathrm{~S} 30, \mathrm{O} 31$ and $\mathrm{O} 32$ for $\mathrm{C} 2$ and $\mathrm{O} 7$ for $\mathrm{C} 3$ have high values of $f_{k}^{-}$, making their atoms preferential sites for electrophilic attacks. However, The preferred site for electrophilic attack is the atom in the molecule where the value of Fukui function $f_{k}^{-}$is the highest, the values of $f_{k}^{-}$of the Sulfur atom in C2 are significantly higher than those of the oxygen in $\mathrm{C} 1$ and $\mathrm{C} 3$, which gives $\mathrm{C} 2$ greater adsorption on the surface of mild steel in comparison with $\mathrm{C} 1$ and $\mathrm{C} 3$ respectively. Especially since Sulfur atoms also have high values of $f_{k}^{+}$, this double character is at the origin of very important adsorption sites, which may explain the high values of the experimental inhibitory efficiencies of $\mathrm{C} 2$ compared to $\mathrm{C} 1$ and $\mathrm{C} 3$.

\section{Conclusion}

The studied Cs 1, 2 and 3, inhibit corrosion of mild steel in $1 \mathrm{M} \mathrm{HCl}$. The inhibition efficiencies determined by gravimetric study, Tafel polarization, EIS methods and quantum chemical study at B3LYP / 6-31G (d,p). All these methods results show that C2 is the best inhibitor in the oxazolic series. Reason why the Sulfur compounds were found very effective corrosion inhibitors for mild steel in the acid solution, since the Sulfur atom is a stronger electron donor than most heteroatom's. However, compounds containing both nitrogen and Sulfur atoms have been found to be better inhibitors than those containing either the heteroatom alone. The Langmuir adsorption isotherm and the negative value of $\Delta G_{\text {ads }}$ indicate that these compounds inhibit corrosion by both physical and chemical adsorption for $\mathrm{C} 1$, however $\mathrm{C} 2$ and $\mathrm{C} 3$ act by chemisorption. 


\section{References}

1. A. Zarrouk, B. Hammouti, T. Lakhlifi, M. Traisnel, H. Vezin and F. Bentiss, Corros. Sci., 2015, 90, 572.

2. N. Patni, S. Agarwal and P. Shah, Chin. J. Eng., 2013, 2013, 10.

3. A.S. Fouda and A.S. Elithy, Corros. Sci., 2009, 51, 868

4. P. Udhayakala, T.V. Rajendiran and S. Gunasekaran, J. Comput. Methods Mol. Des., 2012, $2,1$.

5. A. Popova, M. Christov and A. Vasilev, Corros. Sci., 2007, 49, 3290.

6. H.H. Hassan, E. Abdelghani and M.A. Amin, Electrochim. Acta, 2007, 52, 6359.

7. M.A. Quaraishi, J. Rawat and M. Ajmal, J. Appl. Electrochem., 2000, 30, 745.

8. A. Ghazoui, N. Benchat, F. El-Hajjaji, M. Taleb, Z. Rais, R. Saddik, A. Elaatiaoui and B. Hammouti, J. Alloys Compd., 2017, 693, 510.

9. G. Avci, Colloids Surf. A. 2008, 317, 730.

10. K. Ismaily Alaoui, F. El Hajjaji, M.A. Azaroual, M. Taleb, A. Chetouani, B. Hammouti, F. Abrigach, M. Khoutoul, Y. Abboud, A. Aouniti and R. Touzani, J. Chem. Pharm. Res., 2014, 6, 63.

11. N. Anusuya, P. Sounthari, J. Saranya, K. Parameswari and S. Chitra, Orient. J. Chem., 2015, 31, 1741.

12. B.P. Markhali, R. Naderi, M. Sayebani and M. Mahdavian, Anti-Corros. Methods Mater., 2014, 61, 300.

13. M. M. Antonijević, S. M. Milić and M. B. Petrović, Corros. Sci., 2009, 51, 1228.

14. F. El-Hajjaji, M.E. Belghiti, B. Hammouti, S. Jodeh, O. Hamed, H. Lgaz and R. Salghi, Port. Electrochim. Acta, 2018, 36, 197.

15. S. El Arrouji, K.I. Alaoui, A. Zerrouki, S. El Kadiri, R. Touzani, Z. Rais, M.F. Baba, M. Taleb, A. Chetouani and A. Aouniti, J. Mater. Environ. Sci., 2016, 7, 299.

16. A. Guendouz, N. Missoum, A. Chetouani, S.S. Al-Deyab, B.B. Cheikhe, N. Boussalah, B. Hammouti, M. Taleb and A. Aouniti, Int. J. Electrochem. Sci., 2013, 8, 4305.

17. K.I. Alaoui, F. Ouazzani, Y. kandri rodi, M.A. Azaroual, Z. Rais, M.F. Baba, M. Taleb, A. Chetouani, A. Aouniti and B. Hammouti, J. Mater. Environ. Sci., 2016, 7, 244.

18. I.B. Obot and N.O. Obi-Egbedi, Corros. Sci., 2010, 52, 657.

19. M.J. Frisch, G.W. Trucks, H.B. Schlegel, G.E. Scuseria, M.A. Robb, J.R. Cheeseman, G. Scalmani, V. Barone, B. Mennucci, G.A. Petersson, H. Nakatsuji, M. Caricato, X. Li, H.P. Hratchian, A.F. Izmaylov, J. Bloino, G. Zheng, J.L. Sonnenberg, M. Hada, M. Ehara， K. Toyota， R. Fukuda，J. Hasegawa， M. Ishida，T. Nakajima，Y. Honda, O. Kitao, H. Nakai, T. Vreven, J.A. Montgomery, Jr., J.E. Peralta, F. Ogliaro, M. Bearpark， J.J. Heyd， E. Brothers， K.N. Kudin， V.N. Staroverov， R. Kobayashi, J. Normand, K. Raghavachari, A. Rendell, J.C. Burant, S.S. Iyengar, J. Tomasi, M. Cossi, N. Rega, J.M. Millam, M. Klene, J.E. Knox, J.B. Cross, V. Bakken, C. Adamo, J. Jaramillo, R. Gomperts, R.E. Stratmann, O. Yazyev, A.J. Austin, R. Cammi, C. Pomelli, J.W. Ochterski, R.L. Martin, K. Morokuma, V.G. Zakrzewski, 
G.A. Voth, P. Salvador, J.J. Dannenberg, S. Dapprich, A.D. Daniels, Ö. Farkas, J.B. Foresman, J.V. Ortiz, J. Cioslowski and D.J. Fox, Gaussian 09, Revision E.01, Gaussian, Inc., Wallingford CT, 2009.

20. C. Lee, W. Yang and R.G. Parr, Phys. Rev. B, 1988, 37, 785.

21. W. Wang and W.J. Mortier, J. Am. Chem. Soc., 1986, 108, 5708.

22. K.F. Khaled, Electrochim. Acta, 2010, 22, 6523.

23. M.A. Amin, M.A. Ahmed, H.A. Arida, T. Arslan, M. Saracoglu and F. Kandermirli, Corros. Sci., 2011, 53, 540.

24. K.F. Khaled, S.S. Abdel-Rehim and G.B. Sakr, Arabian J. Chem., 2012, 5, 213.

25. E. McCafferty, Corros Sci., 2005, 47, 3202.

26. B. Zerga, R. Saddik, B. Hammouti, M. Taleb, M. Sfaira, M. EbnTouhami, S.S. AlDeyab and N. Benchat, Int. J. Electrochem. Sci., 2012, 7, 631.

27. H.-L. Wang., Corros. Sci., 2004, 46, 2455.

28. A.K. Satapathy, G. Gunasekaran, S.C. Sahoo, K. Amit and P.V. Rodrigues, Corros. Sci., 2009, 51, 2848.

29. K.C. Emeregül and M. Hayvalí, Corros. Sci., 2006, 48, 797.

30. S. Muralidharan, M.A. Quraishi and S.V.K. Iyer, Corros. Sci., 1995, 37, 1739.

31. M.S. Abdelaal and M.S. Morad, Br. Corros. J. 2001, 36, 253.

32. Y.E. Louadi, F. Abrigach, A. Bouyanzer, R. Touzani, A. El Assyry, A. Zarrouk and B. Hammouti, Port. Electrochim. Acta, 2017, 35, 159.

33. A.Y. Musa, A.A.H. Kadhum, A.B. Mohamad, A.R. Daud, M.S. Takriff and S.K. Kamarudin, Corros. Sci., 2009, 51, 2393.

34. I.D. Raistrick, D.R. Franceschetti and J.R. Macdonald, Impedance Spectroscopy: Theory, Experiment, and Applications, Eds. E. Barsoukov and J.R. Macdonald, 2nd Edition, John Wiley \& Sons, New Jersey, 2005.

35. F.B. Growcock and J.H. Jasinski, J. Electrochem. Soc., 1989, 136, 2310.

36. B. Zerga, A. Attayibat, M. Sfaira, M. Taleb, B. Hammouti, M. EbnTouhami, S. Radi and Z. Rais, J. Appl. Electrochem., 2010, 40, 1575.

37. K.F. Khaled, Electrochim. Acta, 2008, 53, 3484.

38. E. Ech-chihbi, M.E. Belghiti, R. Salim, H. Oudda, M. Taleb, N. Benchat, B. Hammouti and F. El-Hajjaji, Surf. Interfaces, 2017, 9, 206.

39. F. El-Hajjaji, R.A. Belkhmima, B. Zerga, M. Sfaira, M. Taleb, M. EbnTouhami, B. Hammouti, S.S. Al-Deyab and Eno Ebenso, Int. J. Electrochem. Sci., 2014, 9, 4721.

40. K.F. Khaled, O.A. Elhabibc, A. El-mghrabya, O.B. Ibrahim and Magdy A. M. Ibrahim, J. Mater. Environ. Sci., 2010, 1, 139.

41. C. Verma, M.A. Quraishi, K. Kluza, M. Makowska-Janusik, L.O. Olasunkanmi and E.E. Ebenso, Sci. Rep., 2017, 7, 44432.

42. S. Andreani, M. Znini, J. Paolini, L. Majidi, B. Hammouti, J. Costa and A. Muselli, J. Mater. Environ. Sci., 2016, 7, 187.

43. A. Popova, Corros. Sci., 2007, 49, 2144. 
44. J. O'M. Bockris and A.K.N. Reddy, Modern Electrochemistry, Plenum Press, New York, 1977, vol. 2, 1267.

45. M. Yadav, S. Kumar, T. Purkait, L.O. Olasunkanmi, I. Bahadur and E.E. Ebenso, J. Mol. Liq., 2016, 213, 122.

46. S. Lahmidi, A. Elyoussfi, A. Dafali, H. Elmsellem, N.K. Sebbar, L. El Ouasif, A.E. Jilalat, B. El Mahi, E.M. Essassi, I. Abdel-Rahman and B. Hammouti, J. Mater. Environ. Sci., 2017, 8, 225.

47. T. Szauer and A. Brandt, Electrochim. Acta, 1981, 26, 1209.

48. I. Langmuir, J. Am. Chem. Soc., 1947, 39, 1848.

49. B. Zerga, B. Hammouti, M. EbnTouhami, R. Touir, M. Taleb, M. Sfaira, M. Bennajeh and I. Forssal, Int. J.Electrochem. Sci., 2012, 7, 471.

50. W.J. Hehre, L. Radom, P.V.R. Schleyer and A.J. Pople, Ab Initio Molecular Orbital Theory, Wiley-Interscience, New York, 1986. doi: 10.1002/jcc.540070314

51. J.F. Janak, Phys. Rev. B, 1978, 18, 7165.

52. I. Chakib, H. Elmsellem, N.K. Sebbar, S. Lahmidi, A. Nadeem, E.M. Essassi, Y. Ouzidan, I. Abdel-Rahman, F. Bentiss and B. Hammouti, J. Mater. Environ. Sci., 2016, 7, 1866.

53. F. El-Hajjaji, M. Messali, A. Aljuhani, M.R. Aouad, B. Hammouti, M.E. Belghiti, D.S. Chauhan and M.A. Quraishi, J. Mol. Liq., 2018, 249, 997.

54. S.Kr. Saha, A. Hens, A.R. Chowdhury, A.Kr. Lohar, N.C. Murmu and P. Banerjee, Can. Chem. Trans., 2014, $2,489$.

55. A. Bouoidina, F. El-Hajjaji, M. Drissi, M. Taleb, B. Hammouti, I.L. Chung, S. Jodeh and H. Lgaz, Metall. Mater. Trans. A, 2018. doi: 10.1007/s11661-018-4828-4 